\title{
Saneamento básico na região oeste do Paraná
}

\begin{abstract}
Saneamento básico são conjuntos de procedimentos que visam proporcionar uma situação higiênica saudável para a população, através de atividades que estão relacionadas ao abastecimento de água, coleta de esgotos, manejo de resíduos sólidos e águas pluviais visando sempre o bem-estar da população. Um saneamento ambiental inadequado pode provocar uma série de doenças que são transmitidas através do contato com a água. Nesse artigo procurou-se mostrar através dos dados do Sistema Nacional de Informações sobre Saneamento a atual situação do saneamento básico na região oeste do Paraná nos sistemas de abastecimento de água, coleta de esgotos sanitários, coleta de resíduos sólidos e disposição final. A partir dos dados levantados, foram elaboradas tabelas de resumo com as informações obtidas das cinquenta cidades da região oeste do Paraná, através dessa tabela foi criado os mapas temáticos para melhor visualizar as informações obtidas. Os resultados obtidos evidenciaram que o saneamento básico na região ainda é ineficiente em grande parte das cidades, onde a maioria não apresenta dados satisfatórios de atendimento a redes de esgoto. Em relação à coleta dos resíduos sólidos, é necessário que as cidades que ainda dispõe de lixões de adequem à legislação. No setor de abastecimento de água a maioria das cidades apresentou dados positivos, onde grande parte da população é atendida com água potável.
\end{abstract}

Palavras-chave: Saneamento; Saúde Pública; Doenças.

\section{Basic sanitation in the west region of Paraná}

\begin{abstract}
Basic sanitation are sets of procedures that aim to provide a healthy hygienic situation for the population, through activities that are related to water supply, sewage collection, solid waste management and rainwater, always aiming the well being of the population. Inadequate environmental sanitation can cause a number of diseases that are transmitted through contact with water. In this article, we tried to show through the data of the National Sanitation Information System the current situation of basic sanitation in the western region of Paraná in water supply systems, sanitary sewage collection, solid waste collection and final disposal. From the data collected, summary tables were elaborated with the information obtained from the fifty cities of the western region of Paraná. Through this table thematic maps were created to better visualize the information obtained. The results showed that basic sanitation in the region is still inefficient in most cities, where most do not present satisfactory data on sewage services. In relation to the collection of solid waste, it is necessary that cities that still have dumps to comply with legislation. In the water supply sector most cities presented positive data, where a large part of the population is served with drinking water.
\end{abstract}

Keywords: Sanitation; Public Health; Diseases.

\section{Topic: Engenharia Sanitária}

Reviewed anonymously in the process of blind peer.

Jennifer Regina Llera Leiva Lemos

Faculdade União das Américas, Brasil

http://lattes.cnpq.br/1411695741945889

jennifer rll@hotmail.com

\section{Caroliny Matinc}

Universidade do Vale do Taquari, Brasil http://lattes.cnpq.br/1140817732648349 caroliny.matinc@gmail.com

\section{Wallington Felipe de Almeida}

Faculdade União das Américas, Brasil

http://lattes.cnpq.br/7338518496672339

wall felipe@hotmail.com

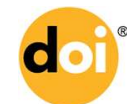

DOI: 10.6008/SPC2179-6858.2017.003.0014
Received: 14/03/2017

Approved: 12/05/2017

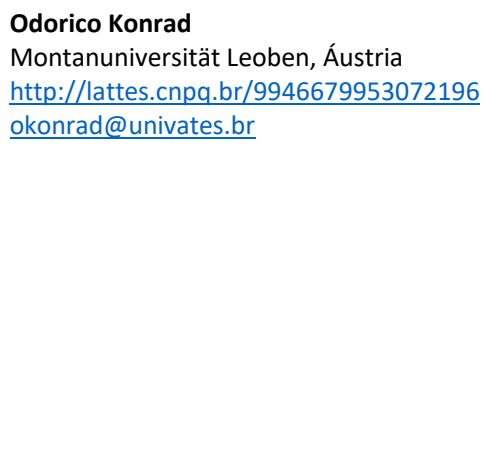

Referencing this:

LEMOS, J. R. L. L.; MATINC, C.; ALMEIDA, W. F.; KONRAD, O..

Saneamento básico na região oeste do Paraná. Revista IberoAmericana de Ciências Ambientais, v.8, n.3, p.151-159, 2017. DOI: http://doi.org/10.6008/SPC2179-6858.2017.003.0014 


\section{INTRODUÇÃO}

Segundo Ribeiro et al. (2010), saneamento é o controle de todos os fatores que podem exercer efeitos nocivos sobre o bem estar físico, mental e social, em outras palavras é um conjunto de ações que tem por objetivo alcançar a salubridade ambiental. A salubridade ambiental é o estado de saúde normal em que se vive a população urbana e rural, tanto no que se refere a sua capacidade de prevenir, inibir ou impedir a ocorrência de doenças, epidemias ou endemias que podem ser veiculadas pelo meio ambientes, quanto no seu potencial de impulsionar o aperfeiçoamento de condições que sejam favoráveis ao gozo de saúde e bem estar (GUIMARÃES et al., 2007).

O saneamento básico de qualidade é garantido por lei para toda a população, mas não é o que se tem encontrado na maioria das cidades do país, nas quais ainda existem cidades em que a população não dispõe de sistemas de tratamento de água adequado, muito menos sistemas de coleta dos esgotos. A questão da disposição dos resíduos também é preocupante, visto que ainda existem muitos lixões ativos espalhados pelo país, conforme a Lei $\mathrm{n}^{\circ} 12.305$ de 02 de agosto de 2010, o prazo para a disposição adequada dos resíduos deveria ter sido implantado em até 4 anos após a publicação da lei, prazo que venceu no ano de 2014 (BRASIL, 2010).

De acordo com a Lei $n^{\circ} 11.445$ de 05 de janeiro de 2007, que estabelece diretrizes para o saneamento básico e para as políticas de saneamento básico, tem-se como definição de saneamento o conjunto de serviços, infraestruturas e instalações operacionais dos serviços de abastecimento de água de qualidade, esgotamento sanitário, drenagem urbana e coleta e destinação de resíduos sólidos (BRASIL, 2007). Ainda segundo a Lei, um dos princípios básicos é a universalização dos serviços para que toda a população possa ter acesso à água potável, sistemas de coleta e tratamento de esgotos domésticos, manejo de resíduos sólidos e águas pluviais (BRASIL, 2007).

A Lei $n^{\circ} 8.080$ de 19 de setembro de 1990, que criou o Sistema Único de Saúde (SUS), tem como campo de atuação a participação na formulação de políticas e na execução de ações e medidas de saneamento básico. Nesta lei, os níveis de saúde de uma população englobam os aspectos de alimentação, moradia, saneamento básico, meio ambiente, trabalho entre outras. Dessa forma, as medidas de saneamento mostram-se de extrema importância para que haja uma melhoria na qualidade de saúde da população (BRASIL, 1990).

Segundo dados do Sistema Nacional de Informações sobre Saneamento, verifica-se que grande parte dos estados brasileiros já possuem sistemas adequados de abastecimento de água, onde mais $90 \%$ da população já conta com água potável. Apenas no estado do Amapá a situação é preocupante, onde apenas $40 \%$ da população é abastecida com água encanada. Os dados de atendimento a esgotamento sanitário é alarmante em todo o país, somente nos estados do Paraná, São Paulo e Minas Gerais acima de $70 \%$ da população é atendida com rede de esgoto. Os demais estados, a população total atendida varia de $10 \%$ a $69 \%$.

De acordo com os autores Ribeiro et al. (2010), com o passar dos anos e com o desenvolvimento científico e tecnológico, existem várias técnicas que podem ser utilizadas para resolver os problemas em 
relação ao saneamento básico. Porém, com o crescimento da população, aumenta também a procura e consumo de materiais provenientes do meio ambiente, como por exemplo, a água para abastecimento, que vem sendo cada vez mais consumida, e tem-se tornado um recurso cada vez mais escasso.

De acordo com a NBR 9648 (ABNT, 2004), o esgoto sanitário é o "despejo líquido constituído de esgotos doméstico e industrial, água de infiltração e a contribuição pluvial parasitária". A norma define ainda esgoto doméstico sendo "despejo líquido resultante do uso da água para higiene e necessidades fisiológicas humanas".

É comum nos municípios do Brasil, a implantação de sistema de abastecimento de água sem a implantação também de sistemas de tratamento de esgotos. Uma vez que um aumento na taxa de consumo de água após a disponibilização de água encanada, é normalmente acompanhada de um aumento dos efluentes gerados, que são geralmente lançados em fossas sépticas, sarjetas e mananciais (PHILLIPI JUNIOR, 2005).

Os resíduos sólidos têm sua definição, conforme NBR 10004 (ABNT, 2004), como sendo os resíduos nos estados sólidos e semissólidos que resultam de atividades de origem doméstica, hospitalar, industrial, comercial, agrícola, de serviços e varrições. Outra definição de resíduos sólidos aparece na Agenda 21 como sendo, todos os restos domésticos e resíduos que não sejam perigosos, como os comerciais e institucionais, lixos de ruas e entulhos. Os sistemas de resíduos sólidos são conjuntos de estruturas e serviços na qual o objetivo é solucionar o manejo e a destinação de resíduos de forma segura e viável, as principais atividades básicas são a coleta, o acondicionamento, o transporte e a disposição final dos resíduos (OLIVEIRA, 1992).

A maioria das cidades no Brasil não apresenta infraestruturas adequadas para o manuseio dos resíduos sólidos, onde existem soluções ambientais sanitárias corretas, elas resumem-se em coletar os resíduos das residências e aterrá-los (PHILLIPI JUNIOR, 2005).

A geração de resíduos sólidos no país foi de $78,6 \mathrm{mi}$ de toneladas, estima-se que cada habitante consumiu aproximadamente $387,63 \mathrm{~kg}$ de lixo durante todo o ano. De todo esse resíduo gerado apenas $90,6 \%$ foram coletados, com isso pouco mais de 7 milhões de toneladas deixaram de ser coletados, e provavelmente tiveram seu destino em locais impróprios para descarte (ABRELPE, 2014).

A Política Nacional de Resíduos Sólidos, que foi instituída pela Lei n 12.305, de 02 de agosto de 2010, norteia alguns princípios básicos de não geração, reutilização, reciclagem, tratamento e disposição final dos resíduos sólidos. Apresenta também os planos e programas que deverão ser feitos de gerenciamento dos resíduos. Ainda segundo a PNRS, o ano de 2014 seria o prazo final para o fim dos lixões no Brasil, quatro anos após a instituição da lei (BRASIL, 2010).

Segundo Phillipi Junior (2005), as ações de saneamento básico devem ser inter-relacionadas, de forma que a implantação de alguma atividade poderá comprometer a eficiência de outras atividades, por exemplo, um município que tenha ausência de sistema de tratamento de esgoto, quando este for lançado no manancial poderá resultar na contaminação do mesmo, que por sua vez poderá inviabilizar ou encarecer o processo de abastecimento de água. 
De acordo com Kronemberger (2014), cerca de $2 \mathrm{mi}$ de crianças morrem no mundo por diarreia; nos países mais carentes, é a terceira causa de morte em crianças menores de 5 anos. Ainda de acordo com Kronemberger (2014), os indicadores de saúde são importantes para se conhecer, monitorar e avaliar a qualidade e saúde da população.

Heller et al. (2003), em seus estudos realizados na cidade de Betim/MG, destacaram que a incidência de diarreia é diretamente proporcional à presença de água de esgotos a céu aberto pelas ruas da cidade, ou seja, pela falta de sistemas de coleta e tratamento de esgotos. Segundo Macedo (2007), a água pode servir de veículo para transmissão de uma série de doenças causadas por microrganismos, que podem ser resultantes da ingestão de água contaminada ou utilização de água poluída para irrigação, pesca e recreação. Ainda segundo o autor, aproximadamente $80 \%$ das doenças que afetam os países são devidas ao consumo de água de má qualidade.

Para Tucci (2001) as doenças de veiculação hídrica podem ocorrer devido a quatro fatores: à falta de água tratada no abastecimento da população, onde a diarreia é a doença mais frequente; a doenças que têm relação com a higiene das pessoas; à doenças relacionadas com o ambiente e disposição de água, como dengue, malária e esquistossomose; e à doenças relacionadas às inundações, como leptospirose. Segundos estudos realizados por Teixeira et al. (2006), a respeito da associação entre saneamento e saúde nos estados brasileiros, foi constatado que o índice de mortalidade infantil, mortalidade proporcional por doença de diarreias aguda em crianças menores de cinco anos e doenças infecciosas e parasitárias estavam diretamente associadas com déficits na cobertura do saneamento básico.

Motta (2005) relacionou em seus estudos a incidência de mortalidade infantil com os serviços de saneamento básico, concluindo que o aumento de $1 \%$ em investimentos na área de saneamento reduziria aproximadamente $2,5 \%$ a taxa de mortalidade infantil. Diante do exposto o presente estudo tem como objetivo identificar o atual cenário da região oeste do Paraná em três pilares do saneamento: abastecimento de água, esgotamento sanitário e coleta de resíduos sólidos verificando se as cidades possuem sistemas adequados que garantam saúde para a população e preservação do meio ambiente.

\section{METODOLODGIA}

\section{Área geográfica abrangida}

A pesquisa teve como objetivo estudar 50 municípios que compõe a região oeste do Paraná, com uma população aproximada de 1.291.492 habitantes. A mesorregião oeste do Paraná é agrupada em três microrregiões:

Microrregião de Cascavel sendo eles: Anahy, Boa Vista da Aparecida, Braganey, Cafelândia, Campo Bonito, Capitão Leônidas Marques, Cascavel, Catanduvas, Corbélia, Diamante do Sul, Guaraniaçu, Ibema, Iguatu, Lindoeste, Nova Aurora, Santa Lúcia, Santa Tereza do Oeste, Três Barras do Paraná;

Microrregião de Foz Do Iguaçu: Céu Azul, Foz do Iguaçu, Itaipulândia, Matelândia, Medianeira, Missal, Ramilândia, Santa Terezinha de Itaipu, São Miguel do Iguaçu, Serranópolis do Iguaçu, Vera Cruz do Oeste; e 
Microrregião de Toledo: Assis Chateaubriand, Diamante d'Oeste, Entre Rios do Oeste, Formosa do Oeste, Guaíra, Iracema do Oeste, Jesuítas, Marechal Cândido Rondon, Maripá, Mercedes, Nova Santa Rosa, Ouro Verde do Oeste, Palotina, Pato Bragado, Quatro Pontes, Santa Helena, São José das Palmeiras, São Pedro do Iguaçu, Terra Roxa, Toledo, Tupãssi.

\section{Delineamento da pesquisa}

Esta pesquisa se desenvolveu de forma bibliográfica do tipo descritiva, tendo sido utilizado o banco de dados do Sistema Nacional de Informações sobre Saneamento (BRASIL, 2014) de onde foram coletados os dados referentes à população total abastecida por abastecimento de água, coleta de esgotos, coleta de resíduos sólidos e destinação dos resíduos.

\section{Coleta dos dados}

Para cada município da região oeste do Paraná, foram coletados dados acerca da situação do saneamento básico para compor uma tabela de resumo com as seguintes informações: população total residente no município; população atendida por coleta de lixo; população com acesso ao abastecimento de água; população que possui rede de coleta de esgoto; população atendida por coleta de resíduos sólidos; e destino dos resíduos coletados. A partir dessas informações foi calculada a porcentagem da população que é atendida por cada serviço.

A partir da tabela obtida, foram elaborados três mapas temáticos para facilitar o entendimento dos dados. Foi utilizado o programa QGIS 2.14 versão LTR para mapear as cidades da região oeste do Paraná conforme o atendimento aos serviços de saneamento. A partir dos resultados obtidos com a coleta dos dados e a elaboração dos mapas, foi feita uma análise da situação do saneamento em cada município, analisando a população que é atendida pelos serviços de saneamento, verificando assim a eficiência ou não desses serviços oferecidos à população.

\section{DISCUSSÃO TEÓRICA}

\section{Avaliação do sistema de abastecimento de água}

Entre os serviços de saneamento básico, o abastecimento de água na microrregião de Foz do Iguaçu, dos onze municípios que compõe essa região, oito apresentaram acesso à água potável para mais de $80 \%$ da sua população. Apenas os municípios de Missal, Ramilândia e Serranópolis do Iguaçu apresentaram acesso ao abastecimento de $58 \%, 56 \%$ e $70 \%$ respectivamente. Os três municípios que apresentaram baixo acesso ao abastecimento, apresentam uma população de até 10.000 habitantes, e por serem cidades de pequeno porte acabam não tendo tantos investimentos por conta dos custos de implantação e manutenção. Os municípios de Foz do Iguaçu, Medianeira e Santa Terezinha foram os melhores avaliados com atendimento a $99 \%$ da população.

Nos municípios da microrregião de Cascavel, quatro cidades se destacaram, apresentando atendimento de $99 \%$ de abastecimento de água para a população: Cafelândia, Cascavel, Ibema e Santa Tereza 
do Oeste. Apenas a cidade de Diamante do Sul apresentou atendimento de apenas $49 \%$. Os demais municípios atendem a mais de $70 \%$ da população com água potável.

Das 21 cidades da região de Toledo, seis estão entre as melhores com mais acesso ao abastecimento de água, Assis Chateaubriad, Entre Rios do Oeste, Marechal Candido Rondon, Palotina, Pato Bragado e Toledo, estes apresentaram acesso à água de qualidade para 99\% da população habitante nos municípios. A cidade de Santa Helena foi a que apresentou o pior resultado com $54 \%$ da população total atendida. As demais cidades obtiveram atendimento de acima de $64 \%$.

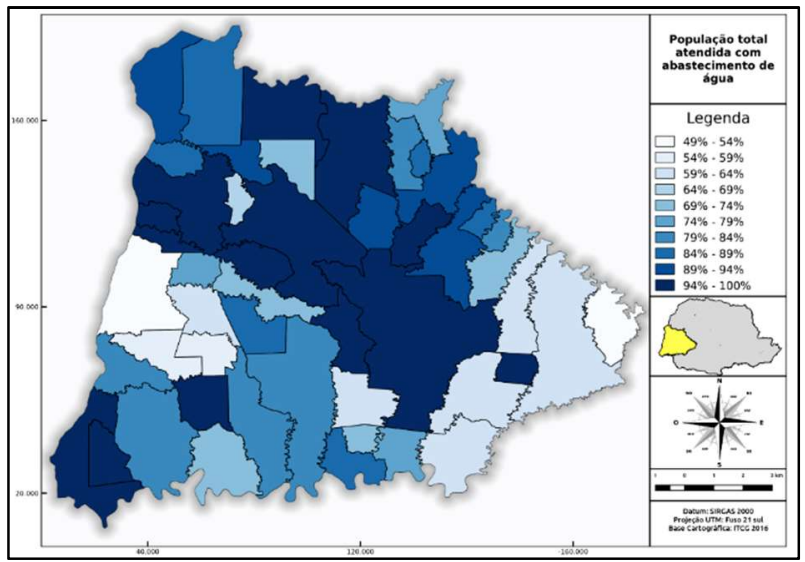

Figura 1: População atendida com sistema de abastecimento de água.

Segundo o Instituto Trata Brasil, a média nacional de atendimento de abastecimento de água é de $82,5 \%$, assim, as cidades do oeste paranaense apontam para um bom gerenciamento desse setor do saneamento, apresentando valores de atendimento superior à média nacional. De acordo com o Ranking do Saneamento (2016) elaborado pelo Instituto Trata Brasil, as cidades de Foz do Iguaçu e Cascavel aparecem entre as cem melhores cidades que apresentam saneamento básico satisfatório. Cascavel ocupa a $18^{\circ}$ posição, e a cidade de Foz do Iguaçu aparece na $33^{\circ}$ posição.

\section{Coleta e destinação final de resíduos sólidos}

Os municípios da região de Foz do Iguaçu, no que se refere à coleta de resíduos sólidos apresentaram resultados satisfatórios, evidenciando que mais de $80 \%$ da população tem acesso ao sistema de coleta de resíduos, os munícipios com melhores resultados foram Céu Azul, Foz do Iguaçu, Itaipulândia, Missal e Santa Terezinha de Itaipu que apresentaram mais de $99 \%$ da população atendida pela coleta de resíduos. 0 município de Serranópolis do Iguaçu foi a cidade que menos atendeu a população, com apenas $51 \%$ de atendimento.

Dos dezoito municípios da região de Cascavel, três foram destaques em atendimento, Cascavel, Ibema e Três Barras do Paraná, que também atendem à $99 \%$ da população. Três cidades obtiveram valores baixos de atendimento, Catanduvas, Diamante do Sul e Lindoeste, com 52\%, 40\% e 57\% respectivamente. Já na microrregião de Toledo, quatro municípios apresentaram atendimento a $100 \%$ da população, Guaíra, Iracema do Oeste, Santa Helena e Terra Roxa. As demais cidades apresentaram atendimento superior a 80\%. Jesuítas, São Jose das Palmeiras e São Pedro do Iguaçu, obtiveram atendimento a apenas $62 \%$ da população. 
A figura 2 apresenta esses dados no mapa. Com relação ao destino final dos resíduos, isso é ilustrado na figura 3.

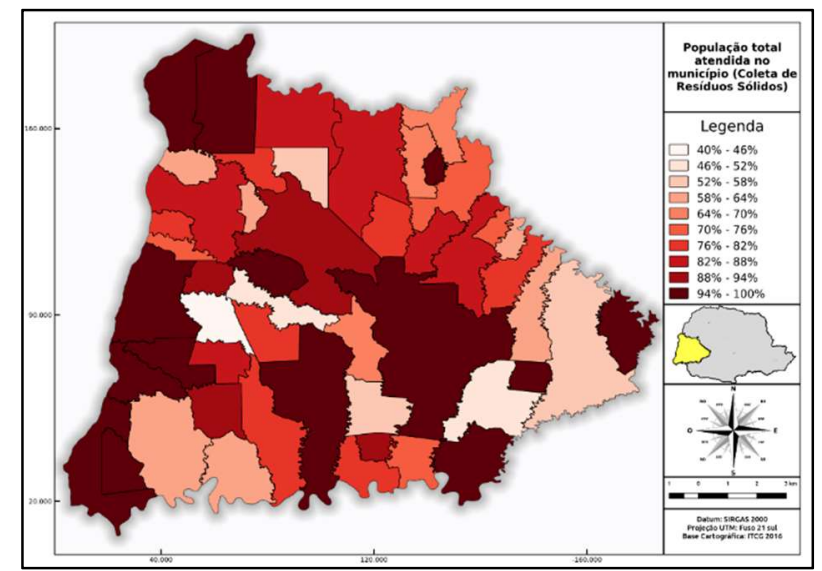

Figura 2. População atendida com sistema de coleta de resíduos sólidos

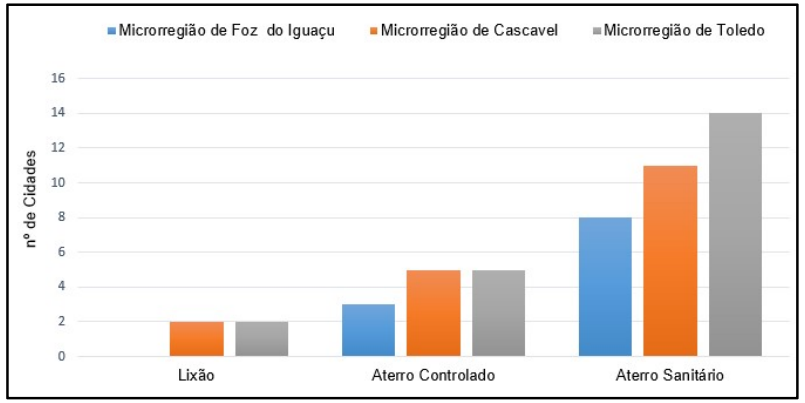

Figura 3. Destinação final dos resíduos sólidos

Com as informações da figura 3, pode-se analisar que na microrregião de Foz, todas as cidades possuem disposição final ou em aterro controlado ou aterro sanitário, Destas, três cidades com destino final o aterro controlado, Céu Azul, Ramilândia e São Miguel do Iguaçu, e oito cidades destinam corretamente seus resíduos nos aterros sanitários, Foz do Iguaçu, Itaipulândia, Matelândia. Medianeira, Missal, Santa Terezinha de Itaipu, Serranópolis do Iguaçu e Vera Cruz do Oeste.

As regiões de Cascavel e Toledo apresentaram 2 cidades cada, com disposição final em lixão, Braganey, Boa Vista da Aparecida, São Jose das Palmeiras e Terra Roxa. Apresentaram também, cinco municípios cada que dispõe seus resíduos sólidos nos aterros controlados e em sua maior parte os municípios que dispõem de forma correta nos aterros sanitários. A região de Toledo apresentou a maior quantidade de cidades que dispõem corretamente os resíduos nos aterros sanitários.

\section{Avaliação do sistema de coleta de esgoto}

A situação da disponibilidade das redes de coleta de esgoto na região oeste do Paraná é preocupante, visto que a falta desse serviço pode gerar inúmeros problemas relacionados à saúde e ao meio ambiente. Os resultados obtidos referentes à coleta de esgoto mostra que ainda existe um grande percurso a ser percorrido, apenas três municípios da região oeste do Paraná apresentaram sistemas de coleta de esgoto que atendam a 78\% da sua população, Foz do Iguaçu, Cascavel e Toledo. 
Nos municípios da região de Foz do Iguaçu, três municípios não apresentaram dados suficientes referentes à coleta de esgoto, Missal, Ramilândia e Serranópolis do Iguaçu. Na região de Cascavel a situação se agrava, onde doze municípios não apresentaram dados mínimos referentes à coleta dos efluentes, e os que possuem atendem a somente $50 \%$ da população residente na cidade. Nas cidades da região de Toledo, 13 municípios não apresentaram dados sobre coleta de esgoto. Apesar dos dados negativos, nas cidades que apresentam a coleta de esgoto, a média de atendimento à população está superior à média nacional que é de $48,6 \%$.

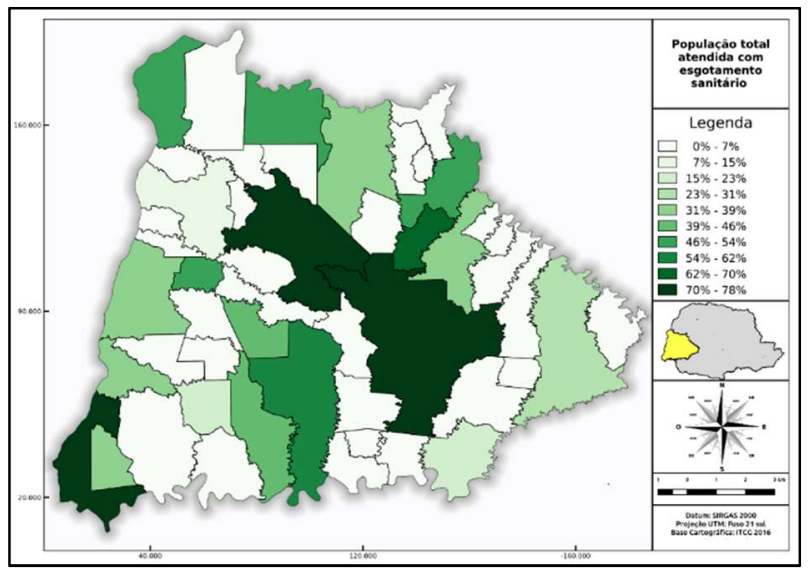

Figura 7: População atendida com sistema de coleta de esgoto.

Os municípios tem gasto pouco em melhorias dos sistemas de esgotamento sanitário, principalmente nas cidades com menor número de habitantes, onde o retorno financeiro não é tão significativo. Devido a essa falta de investimentos, a situação é preocupante, pois a falta desse sistema pode gerar problemas bem maiores, tanto em relação ao meio ambiente, quando esse esgoto é lançado de forma incorreta no solo ou cursos de rio, ou mesmo na saúde da população, ocasionando casos de diarreias e outras doenças de origem hídrica.

\section{CONCLUSÕES}

Por meio desse estudo, observou-se que a região oeste do Paraná apresenta deficiências nos sistemas de saneamento básico, como evidenciaram os mapas de atendimento das cidades que compõem cada região. As cidades de Foz do Iguaçu, Cascavel e Toledo foram as que obtiveram melhores resultados, onde a maioria da população tem acesso aos serviços básicos de saneamento.

É indiscutível a importância do saneamento básico tanto para a prevenção de doenças como para a preservação do meio ambiente. É necessário que se crie condições para que os serviços de saneamento possam ser ampliados desde as grandes cidades, quanto para as pequenas. De acordo com os dados apresentados e as discussões realizadas não ficam dúvidas sobre a importância em investimentos nos sistemas de abastecimento de água, coleta de esgoto e resíduos sólidos para que haja melhoria nas condições de vida da população.

Os investimentos têm sido principalmente em saúde corretiva, ao invés de se investir em saúde preventiva. Segundo a FUNASA (2006) a cada um real investido em saneamento economiza-se quatro reais em saúde. A realidade do saneamento na região oeste do Paraná, apesar de ter obtidos resultados melhores 
do que a realidade nos outros estados brasileiros de modo geral, ainda exige muitos esforços para que o saneamento básico atenda a toda população das cidades.

Melhorias nos sistemas de esgotamento sanitário são, sem dúvida, a prioridade, visto que teve os resultados de atendimento à população mais baixo. Outra melhoria a ser investida, é em relação ao destino dos resíduos sólidos, onde quatro municípios ainda dispõem seus resíduos em lixões. $O$ avanço na área de saneamento ainda está muito lento, visto que, muitas cidades ainda apresentam muitos atrasos nesse setor, onde a população ainda não tem acesso aos serviços básicos de saneamento. $\mathrm{O}$ acesso à esses serviços tem sido pontuais em algumas cidades, enquanto isso, grande parte das demais cidades ainda carece desses serviços básicos.

\section{REFERÊNCIAS}

ABNT. Associação Brasileira de Normas Técnicas. NBR ISO 10004/1987: Resíduos sólidos: Classificação. Rio de Janeiro: ABNT, 2004.

ABNT. Associação Brasileira de Normas Técnicas. NBR ISO 9648/1986: Estudo de concepção de sistemas de esgoto sanitário. Rio de Janeiro: ABNT, 2004.

ABRELPE. Associação Brasileira de Empresas de Limpeza Pública e Resíduos Especiais. Panorama dos resíduos sólidos no Brasil em 2014. São Paulo: ABRELPE, 2014.

BRASIL. Lei Federal n.11.445 de 31 de agosto de 1981. Estabelece diretrizes nacionais para o saneamento básico e dá outras providências. Brasília: DOU, 2007.

BRASIL. Lei Federal n.12305 de 19 de setembro de 1990. Institui a Política Nacional de Resíduos Sólidos; altera a Lei n9.605, de 12 de fevereiro de 1998 e dá outras providências. Brasília: DOU, 2010.

BRASIL. Lei Federal $\mathbf{n . 8 0 8 0}$ de 19 de setembro de 1990 Dispõe sobre as condições para a promoção, proteção e recuperação da saúde, a organização e o funcionamento dos serviços correspondentes e dá outras providências. Brasília: DOU, 1990.

GUIMARÃES, A. J. A.; CARVALHO, D. F.; SILVA, L. D. B. Saneamento básico. Rio de Janeiro: 2007.

HELLER, L.; COLOSIMO, E. A.; ANTUNES, C. M. F. Environmental sanitation conditions and health impact: a case-control study. Revista da Sociedade Brasileira de Medicina Tropical, v.36, n.1, p.41-50, 2003.
KRONEMBERGER, D.. Análise do indicadores de saúde pública associados ao saneamento inadequado no município de Campo Grande (MS) no período de 20032013. Campo Grande: 2014.

MACEDO, J. A. B.. Águas \& Águas. 3. ed. Belo Horizonte: CRQ, 2007

MOTTA, R. S.. Padrão de consumo, distribuição de renda e o meio ambiente no Brasil. In: ENCONTRO ECOECO - políticas públicas e instrumentos econômicos para o desenvolvimento sustentável, 6. Anais. Brasília: IBAMA, 2005.

OLIVEIRA, W. E.. Resíduos sólidos e limpeza pública: saneamento do meio. São Paulo: Fundacentro, 1992.

PHILLIPI JUNIOR, A.. Saneamento, saúde e meio ambiente: fundamentos para um desenvolvimento sustentável. Barueri: Manole, 2005.

RIBEIRO, J. W.; ROOKE, J. M. S.. Saneamento básico e sua relação com meio ambiente e a saúde pública. Juiz de Fora: UFJF, 2010.

TEIXEIRA, J. C.; GUILHERMINO, R. L.. Análise da associação entre saneamento e saúde nos estados brasileiros, empregando dados secundários do banco de dados Indicadores e Dados Básicos para a Saúde: IDB 2003. Engenharia Sanitária e Ambiental, v.11, n.3, p.277-282, 2006.

TUCCI, C. E. M.. Gerenciamento da drenagem urbana. Revista Brasileira de Recursos Hídricos, Porto Alegre, v.7, p.5-27, 2002. 